\title{
Design and Fabrication of a Leak Proof Vacuum Assisted Resin Transfer Mold for manufacturing Fiber Reinforced Plastic Laminate using Product
}

\section{Design Approach}

\author{
${ }^{1}$ Madhav Murthy, ${ }^{2}$ K. Mallikharjuna Babu, ${ }^{3}$ P. Martin Jebaraj \\ ${ }^{1,2,3}$ B.M.S.College of Engineering \\ Bengaluru-560019
}

\begin{abstract}
A polymer composite material is a two phase material made up of a matrix and reinforcement. The constituents must be considered appropriate proportions for the desired properties in the final laminate prepared. Compared to other manufacturing methods of making polymer matrix composites, Resin transfer molding (RTM) allows better control over complex geometries and parts with larger diversities. The mold design becomes an important aspect of the process in RTM as the process is automated and quality of the part made depends on the design of the system . This work focuses on product design approach to designing and fabrication of mold for manufacturing fiber reinforced plastic laminates which is free from vacuum leakage. Although the RTM method is an old method, not much of the literature on optimum designing of the system is available. Product design approach is used in this work as it helps problem solving in a systematic way.
\end{abstract}

Keywords- Resin Transfer Molding, Product Design approach, Mold design, Fiber Reinforced Plastic Laminates.

\section{INTRODUCTION}

Composite materials are multi-phase materials, where the interaction of the two phases gives overall physical and mechanical properties to the laminate prepared. One of the most widely used types of Composite materials is polymer matrix composites. It is made up of a matrix and reinforcement. The combination of fibrous reinforcement in a resin (matrix) is the common type of polymer composites.

Resin Transfer Moulding: It is a closed mold, vacuum assisted process for fabrication of composite laminates. In this process, reinforcement is stacked into the mold cavity which has the shape of the final product. The resin is injected into the mold under vacuum pressure till it gets completely filled. Later the mold can be heated \& the resin polymerizes to become a rigid plastic [1]. The closure of the mold can be done mechanically or by applying vacuum between the two seals in the molds peripheral flange.

Vacuum-assisted resin transfer moulding (V-RTM) is one of the most commonly used manufacturing process for polymer composite materials. The process is performed by infusing liquid resin, which is drawn in by utilizing a differential pressure into the fibers. This method is an out of autoclave method. The V-RTM process was initially developed for manufacturing high quality and large composite parts such as the ship structures. The V-RTM process has its strengths in flexibility and is used for manufacturing complex and large composite parts with good quality. The setup time involved is higher as compared to vacuum bagging and autoclave process. The design of the RTM included the following steps;

a) A study to understand the various parameters regarding the RTM process, and the Vacuum assisted RTM process - literature survey was done on the various parameters such as fluid flow, vacuum sealant, design aspects, port location and size, re-enforcement used and locking mechanisms.

b) A mold box was designed considering the different types of Resin Transfer Moulding (RTM) such as Light Resin Transfer Moulding (LRTM), Vacuum assisted Resin Transfer Moulding (V-RTM), FAST Remotely Actuated Channeling (FASTRAC), Vacuum Induced Preform Relaxation (VIPR), Structural Reaction Injection Moulding (S-RIM), Compression Resin Transfer Moulding (CRTM) and Resin Infusion between Double Flexible Tooling (RIDFT).

c) Fabrication of a mold box using the enhanced parameters as studied from the literature survey has been conducted, and then to fabricate a test specimen using the mold box.

d) To develop an economical and optimized laboratory experimental setup for the Resin Transfer Molding process[2], using the parameters from the literature review to achieve the desired output configuration

\section{PRODUCT DESIGN \& MANUFACTURING (PDM)}

It is one of the concepts used in this work to efficiently carry out the tasks in an optimized way. PDM concerns with generation of concepts, its selection, and application of said concepts into actual work. The following are the steps followed: 
1. Identifying customer needs: i) To establish a RTM setup ii) Optimum port placements iii) Efficient sealing iv) Ease of use

v) Checking effectiveness of the set up.

2. Establishing target specifications : i)Designing a mold box, to fabricate a flat plate of size $300 \times 300 \times 5 \mathrm{~mm}$ ii)Positioning the inlet and outlet ports for resin and vacuum transfer in such a way than most optimum flow and impregnation of the resin through the fibre reinforcement takes place iii)Establishing the RTM setup, with optimized output and ensure low wastage of consumables iv)Fabrication of flat plates of FRP v)Performing tests on the FRP plate based on ASTM D3039M standards.

3. Concept generation: Types of RTM processes

Based on type of RTM process:

- $\quad$ VRTM - the setup consists of a hard bottom mold made of FRP and a vacuum bag as the top mold. The cavity is usually in the bottom mold hence the reinforcement is placed in the required layers in the cavity and the resin is made to flow by providing the appropriate amount of vacuum in the cavity.

- $\quad$ LRTM - It is also a closed mold type process like VRTM that follows the same steps. The only difference is in the material of the top mold. Here the top mold is a hard mold box made of the composite material itself.

i) Initially a circumferential design [3] was considered with a circular cavity to be fabricated. It consisted of a central inlet and a peripheral flanged outlet port ii) A design with a rectangular cavity was considered later on where the resin entered the cavity from one of the shorter edges and leaves from the opposite edge iii) The next design considered was of a square cavity of the required thickness having a peripheral flange to which the resin inlet was to be attached. The outlet port was placed at the centre on the top mold box iv) The next design consists of a flange on only one side of the square cavity connected to the inlet port and an outlet port at the opposite end of the cavity.

Based on sealing the mold : i) Vacuum assisted sealing - Here, a vacuum is used to produce the required sealing between two surfaces ii) Mechanical sealing - Here, a mechanical force is used to bring two surfaces in contact to provide sealing

iii) Electro-magnetic sealing - Here, an electromagnetic chain or ring is used where the magnetic force is used to seal the two surfaces.

4. Concept selection: Based on the requirements/inputs/approval from industry, a suitable concept(s) have be selected which necessitates the following: a) RTM setup b) Production and testing of FRP composites c) Results and inferences d) Concept testing. The practicality of the process has been verified through the literature survey.

5. Setting final specification: Specifications as approved by industry experts as the RTM setup to be made is a miniaturized version. With the inputs from the ANSYS model, \& industry input, the final design is selected.
This design encompasses all the parameters that had to be addressed, \& is very specific in the dimensions set. The final size was set as $540 \times 540 \times 40 \mathrm{~mm}$ for the mold box. This has a $300 \times 300 \mathrm{~mm}$ internal cavity for the component to be molded in. This design also has a few small optimizations, such as universal vacuum port, for both sealing and resin transfer. This model consisted of slots between two vacuum channels, to enable the use of a single vacuum source for both sealing $\&$ resin transfer. The internal cavity depth was set as $3 \mathrm{~mm} \&$ the sealing line depth was set as $8 \mathrm{~mm}$. A plane transparent sheet of glass or silicone rubber can be used as a top mold, effectively sealing off the internal cavity.

6. Project planning: A study is carried out to understand the various parameters regarding the RTM process and the Vacuum assisted RTM process such as material properties, resin flow, design aspects, port placement, etc. The mold box design with optimized parameters, such as efficient sealing, port-placement, productivity is obtained and an experimental setup of the process is established. To create a mold box, and then fabricate a flat FRP plates using the established RTM setup.

7. Economic analysis: Usage of materials required for FRP production - Resin, Fibers, Hardeners, release agents. Epoxy Resin was selected because of its superior qualities, cheaper cost \& better safety regarding health hazards. S type Glass fibre was selected, having bi-directional orientation, because of its popular availability \& pricing. Kevlar \& Carbon fibers were considered, but not considered due to its high costs. The mold box itself was to be made of Acrylic. This was selected because even though Glass was cheaper, machining Glass would have been a very difficult job, prone to major cracking issues. The top mold box was made of Poly-carbonate plastic which has a high flexural ability without cracking, but slightly costlier than acrylic. Acrylic was not selected because of its brittleness. The sealing was done through normal isoprene rubber, which is economical \& widely available.

9. Prototype and Benchmarking: This involves making components/test coupons from the established RTM setup and validating them. It would also involve comparing it with other effective methods of making FRP composite, such as Compression Moulding, SCRIMP, RIFT, etc. A literature survey on various designs regarding efficient sealing, port placement, and uniform flow characteristics was carried out. Based on the survey, several mold designs were developed by Manual drafting and Computer Aided Drafting for the mold boxes, ex: Figure 1. A 3D printed mold box, with basic design parameters was printed to understand the design necessities. 


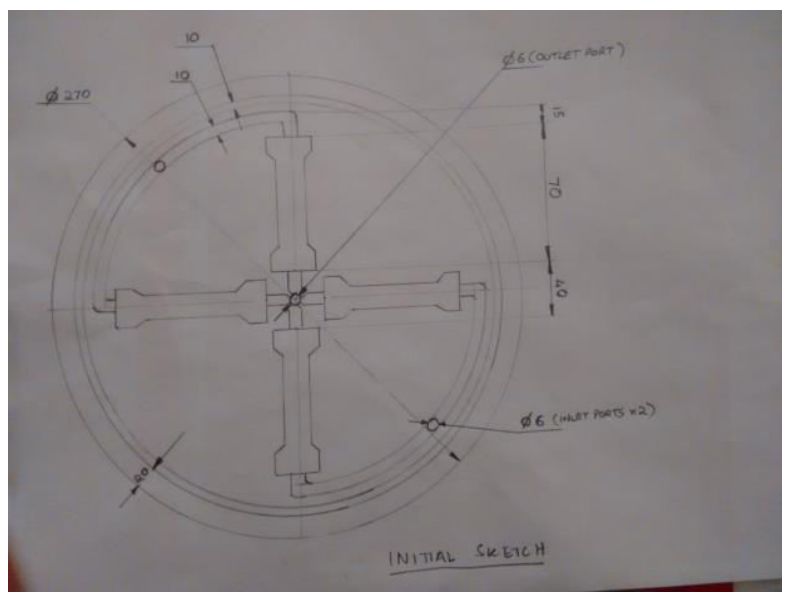

Figure 1. Conceptual mold design

After the initial design parameter selection, the selection of the final parameters had to be done. Sketching was done with different locations for port placements, extended regions for flash and sealing was introduced. After a few initial drawings that were basic, corrections and modifications lead to the mold design that was considered to be finalized. Going along the process of Product Development, the initial design had to be re-worked in order to synchronize with the given requirements. The initial sketch had design faults. So, the second design was made on the basis of the $1^{\text {st }}$ design, but had improved qualities, based on the inputs from industry. This design was considered based on ASTM D3039 Tensile test specimen. Here to improve the production rate four cavities were introduced in the mould design itself. Thus four tensile test specimens could be manufactured in one turn. The outlet for the resin is placed at the centre and the inlet is at the sides. This design ensures complete filling of the cavity. The vacuum pressure at the outlet ensures that there are no resin rich or resin poor regions. Around the mould cavity there is a lining of sealant tube that encloses the cavity and prevents any leakages.

\section{SOFTWARE MODELING}

From the designs and the 3D model, designing was done using CATIA software, in order to facilitate faster designing time \& efficiency as can be seen in figure 2-figure 5.Location of resin injection ports are at the middle in figure 2 , to the left hand side in figure 4 and two ports, one to the left and one to the right hand side as in figure 5 .

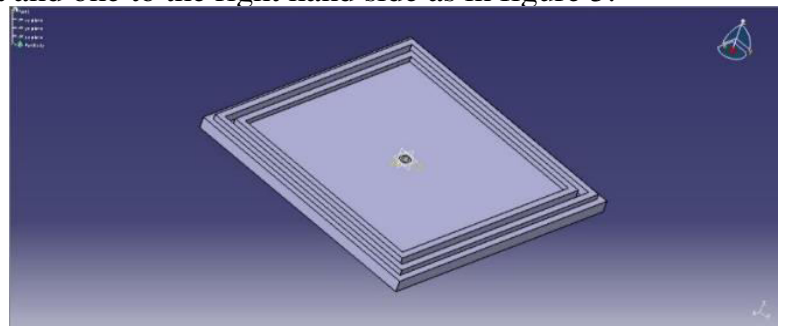

Figure 2. LRTM Male Mold box

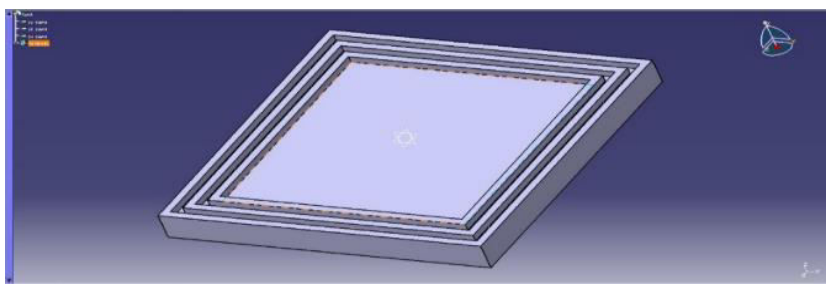

Figure 3. LRTM Female Mold box

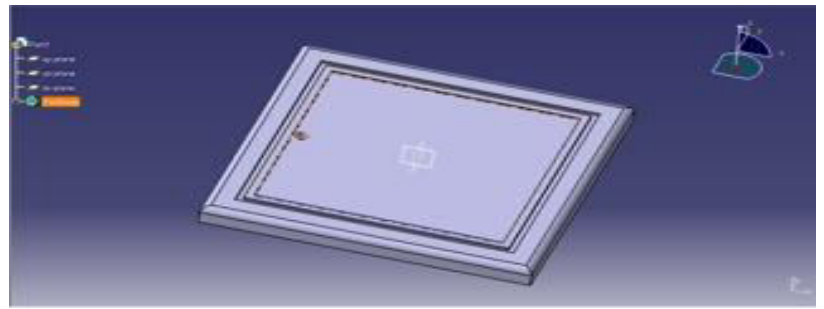

Figure 4. LRTM Model 2

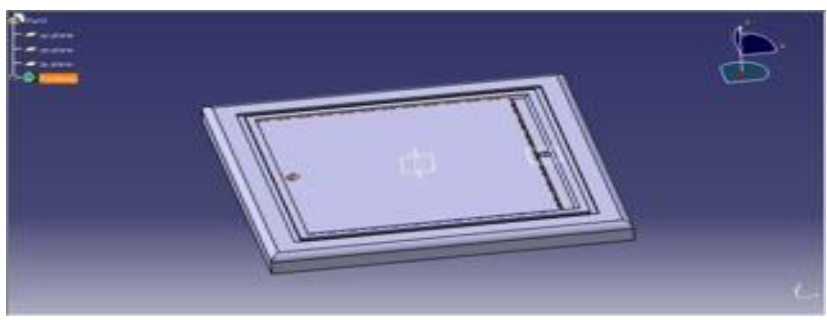

Figure 5. LRTM Model 3

flex at the time when vacuum would be applied inside the closed mould during RTM. Therefore Polycarbonate was selected as the top mould material as it served both purposes.Machining of mold: Acrylic square block of $540 \mathrm{~mm}$ side and $40 \mathrm{~mm}$ depth was carefully CNC machined to obtain the cavities, channels and port cavities. Threading was carried out on a vertical drilling machine using $1 / 8^{\text {th }}$ B.S.P standard drill bit. The top mould or the polycarbonate plate was centrally threaded using the same procedure as mentioned above.

VA-RTM Setup (Design 1)

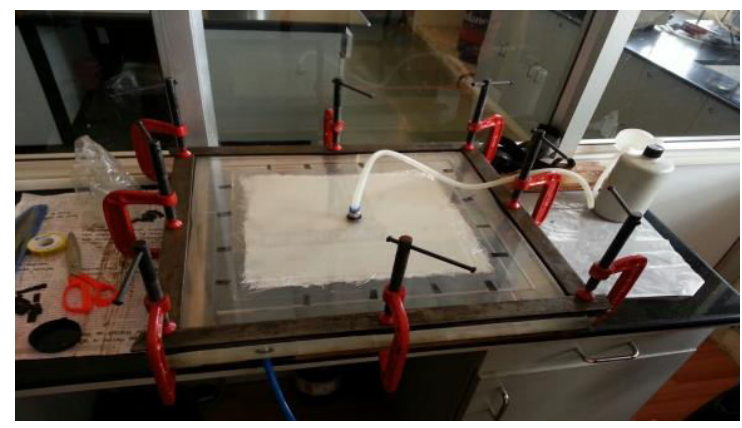

Figure 6. Placement of fibers, sealing \& clamping 
The previous design for the resin transfer molding had a lot of issues due to which the frp laminate could not be made. The major drawbacks in the previous design are vacuum leakage and in correct consideration of cavity depth. This was addressed in consultation with few industry experts.
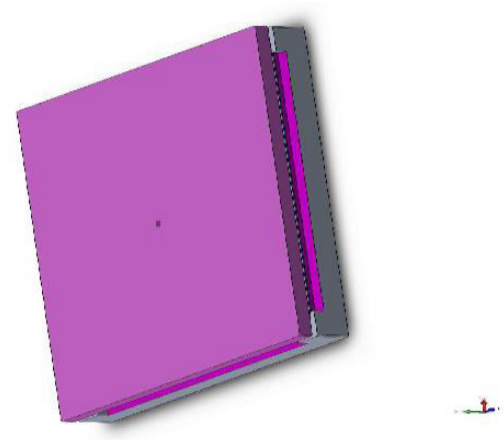

Figure 7. Top view of new mold(design 2) with top mould

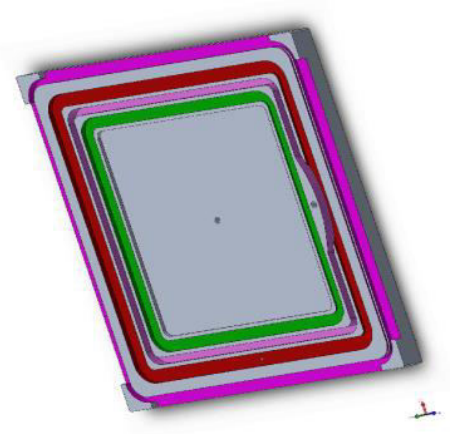

Figure 8 . Top view of new mold without top mould(with cavity)

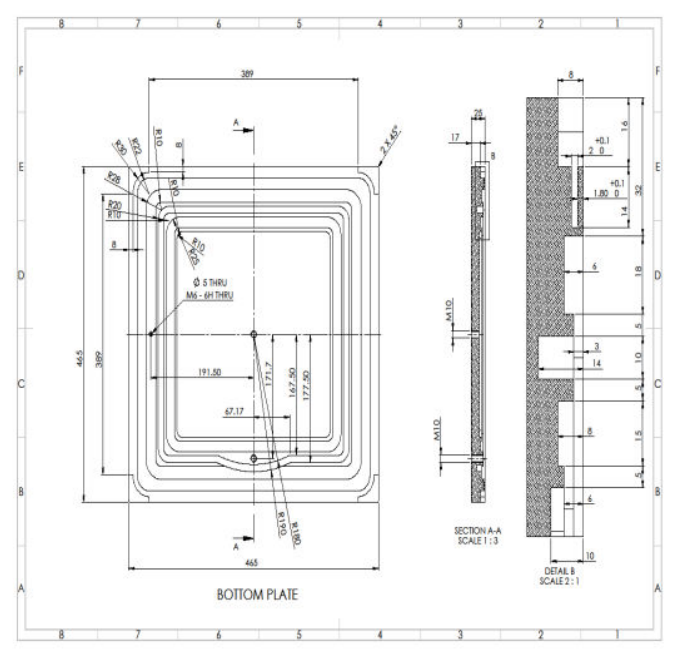

Figure 9. CAD of new resin transfer molding setup (Design 2)

\begin{tabular}{|l|l|}
\hline Properties & Values \\
\hline $\mathrm{E}_{1}$ & $85 \mathrm{GPa}$ \\
\hline $\mathrm{E}_{2}$ & $3.5 \mathrm{GPa}$ \\
\hline $\mathrm{E}_{3}$ & $3.5 \mathrm{GPa}$ \\
\hline$v_{12}$ & 0.2 \\
\hline$v_{23}$ & 0.2 \\
\hline$v_{31}$ & 0.35 \\
\hline G12 & $36 \mathrm{GPa}$ \\
\hline G23 & $36 \mathrm{GPa}$ \\
\hline G31 & $36 \mathrm{GPa}$ \\
\hline Density & $1822 \mathrm{~kg} / \mathrm{m}^{3}$ \\
\hline Fabric thickness & $0.25 \mathrm{~mm}$ \\
\hline
\end{tabular}

Molding setup - top plate

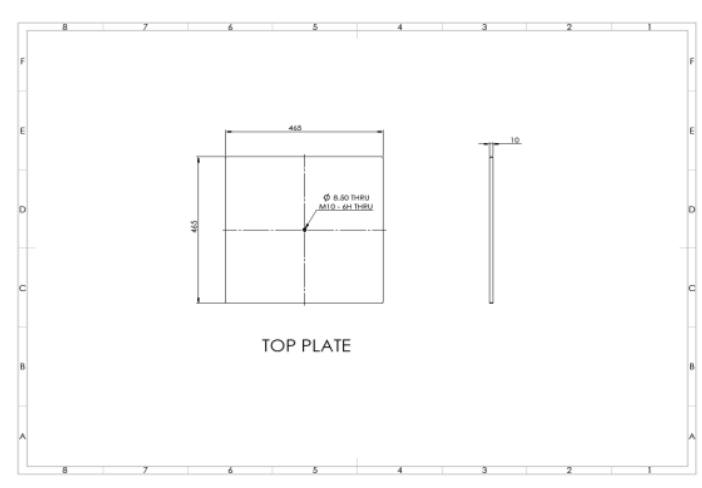

Figure 10. CAD of new resin transfer molding setup- top plate

The new RTM mold setup is fully functional without any leakages and a few laminates are made to test the set up.

TABLE 1: PROPERTIES OF MATRIX AND REINFORCEMENT USED IN TESTING

\begin{tabular}{|l|l|l|l|l|}
\hline $\begin{array}{l}\text { Resin } \\
\text { type }\end{array}$ & $\begin{array}{l}\text { Viscosity } \\
(\text { Pa S at 25 } \\
\left.{ }^{0} \mathrm{C}\right)\end{array}$ & $\begin{array}{l}\text { Density } \\
\left(\mathrm{g} / \mathrm{cm}^{3}\right)\end{array}$ & $\begin{array}{l}\text { Fiber-S Glass, } \\
\text { Bi Directional }\end{array}$ & $\begin{array}{l}\text { Vacuum } \\
\text { Pump Details }\end{array}$ \\
\hline AW106 & 50 & 1.17 & $0.30 \mathrm{~mm}$ & $\begin{array}{l}\text { Double stage } \\
\text { rotary } \\
\text { vacuum } \\
\text { pump of 300 } \\
\text { lpm, 1 hp 3ph } \\
\text { motor }\end{array}$ \\
\hline LY556 & $10-12$ & $\begin{array}{l}1.15 \\
1.20\end{array}$ & $0.30 \mathrm{~mm}$ & \\
\hline CY 230 & 13.5 & 1.2 & $0.30 \mathrm{~mm}$ & \\
\hline
\end{tabular}


TABLE 2: PROPERTIES OF S GLASS BIDIRECTIONAL FABRIC

\begin{tabular}{|c|c|}
\hline Properties & Values \\
\hline $\mathrm{E}_{1}$ & $85 \mathrm{GPa}$ \\
\hline $\mathrm{E}_{2}$ & $3.5 \mathrm{GPa}$ \\
\hline $\mathrm{E}_{3}$ & $3.5 \mathrm{GPa}$ \\
\hline$v_{12}$ & 0.2 \\
\hline$v_{23}$ & 0.2 \\
\hline$v_{31}$ & 0.35 \\
\hline $\mathrm{G} 12$ & $36 \mathrm{GPa}$ \\
\hline $\mathrm{G} 23$ & $36 \mathrm{GPa}$ \\
\hline G31 & $36 \mathrm{GPa}$ \\
\hline Density & $1822 \mathrm{~kg} / \mathrm{m}^{3}$ \\
\hline Fabric thickness & $0.25 \mathrm{~mm}$ \\
\hline
\end{tabular}

\section{CONCLUSION}

Mold design is a critical aspect in design of any system without which the system will not produce accurate products. Product design approach helps in considering various parameters before a product is made which makes the product error free and gains wider acceptance. It can be concluded that cavity depth, vacuum port, mold closure which is leak free are major parameters of a RTM system. Although resin transfer moulding process is not a new method but designing a system free from leakages is a challenge because of so many parameters involved like viscosity of the resin, fabric thickness, vacuum pressure etc. It was also observed that the flow happens radially outwards and the time taken is around 2-3 minutes for mold filling. A resin catch pot is also introduced into the system to avoid back flow into the vacuum pump.

\section{REFERENCES}

[1] Suresh G. Advani \& Kuang-Ting Hsiao, Manufacturing Techniques for Polymer Matrix Composites (PMCs), I Edition, Woodhead Publications Ltd.,2012

[2] Scott M. Rossell, "Fluid Modelling of Resin Transfer Moulding for Composites Material Wind Turbine Blade Structures", SAND2004, Dept. of Chemical Engg., Montana State University, Montana, 2004.

[3] Rutz, CT, "Lessons Learned While Designing Low Volume Closed Mould Processes to replace Open Mould Lamination", Cook Composites \& Polymers (CCP), Kansas City, USA.

[4] Tensile behavior of epoxy based FRP composites under extreme service conditions by Fabio Nardone, Marco Di Ludovico, Francisco J. De Caso y Basalo, Andrea Prota, Antonio Nanni

[5] Standard Test Method for Tensile Properties of Polymer Matrix Composite Materials by ASTM (D3039/3039M \& D638)

[6] Statistical characterization and robust design of RTM processes by Jing Li, Chuck Zhang, Richard Liang, Ben Wang

[7] Eng. ${ }^{\circ}$ Nuno Andre Curado Mateus Correia, "Analysis of the vacuum infusion moulding process", $\mathrm{PhD}$ thesis, University of Nottingham, 2004.

G. O. Young, "Synthetic structure of industrial plastics (Book style with paper title and editor)," in Plastics, 2nd ed. vol. 3, J. Peters, Ed. New York: McGraw-Hill, 1964, pp. 15-64. 